\title{
Long-term noninvasive ventilation in children and adolescents with neuromuscular disorders
}

\author{
U. Mellies*, , R. Ragette $\#$, , C. Dohna Schwake*, H. Boehm*, T. Voit*, H. Teschler ${ }^{\#}$
}

Long-term noninvasive ventilation in children and adolescents with neuromuscular disorders. U. Mellies, R. Ragette, C. Dohna Schwake, H. Boehm, T. Voit, H. Teschler. (C) ERS Journals Ltd 2003.

ABSTRACT: The aim of the current study was to investigate the long-term impact of nocturnal noninvasive (positive-pressure) ventilation (NIV) on sleep, sleep-disordered breathing (SDB) and respiratory function in children and adolescents with progressive neuromuscular disorders (NMD).

Thirty patients $(12.3 \pm 4.1$ yrs) with various inherited NMD were treated with NIV for ventilatory insufficiency $(n=14)$ or symptomatic SDB $(n=16)$. Patients were prospectively followed with sleep studies, spirometry and peak inspiratory muscle pressure. Ten patients were studied before and after 3 nights withdrawal from NIV.

NIV normalised nocturnal gas exchange in all patients and diurnal gas exchange in patients with ventilatory insufficiency. The effects persisted over $25.3 \pm 12.7$ months. Nocturnal transcutaneous partial pressure of carbon dioxide improved from (baseline versus latest control) $7.1 \pm 1.3$ to $5.5 \pm 0.6 \mathrm{kPa}(53.7 \pm 9.9$ to $41.6 \pm 4.8 \mathrm{mmHg})$, diurnal carbon dioxide arterial tension from $6.3 \pm 1.6$ to $5.4 \pm 0.5 \mathrm{kPa}(47.5 \pm 11.9$ to 40.6 $\pm 3.6 \mathrm{mmHg}$ ).

NIV improved respiratory disturbance index, arousals from sleep, nocturnal heart rate and sleep architecture. Vital capacity decreased in five adolescents with Duchenne muscular dystrophy $-183 \pm 111 \mathrm{~mL} \cdot \mathrm{yr}^{-1}$ but remained stable in 25 children with other conditions $\left(8 \pm 78 \mathrm{~mL} \cdot \mathrm{yr}^{-1}\right)$. Three nights withdrawal of NIV in 10 previously stable patients resulted in prompt deterioration of SDB and gas exchange back to baseline but could be instantly normalised by resumption of NIV.

Noninvasive (positive-pressure) ventilation has favourable long-term impact on nocturnal and diurnal gas exchange and sleep and in patients with non-Duchenne neuromuscular disorders on vital capacity as well. It is indicated in children and adolescents with symptomatic sleep-disordered breathing or ventilatory insufficiency due to neuromuscular disorders.

Eur Respir J 2003; 22: 631-636.
*Dept of Pediatrics and Neuropediatrics, University of Essen, "Dept of Pneumology and Sleep Medicine, Ruhrlandklinik, Essen, Germany, and "Dept of Pneumology and Sleep Medicine, Ruhrlandklinik, Essen, Germany.

Correspondence: U. Mellies

University of Essen

Children's Hospital

Dept of Pediatrics and Neuropediatrics

Hufelandstr. 55

D-45122 Essen

Germany

Fax: 492017235727

E-mail: uwe.mellies@uni-essen.de

Keywords: Adolescents

children

neuromuscular disorders

noninvasive positive-pressure ventilation sleep-disordered breathing

Received: April 212003

Accepted after revision: June 32003

Supported by grants from the University of Essen, grant \#107505-0/IFORES, by a research grant founded by VitalAire Deutschland $\mathrm{GmbH}$ and Heinen \& Löwenstein $\mathrm{GmbH}$, and by the Alfried Krupp von Bohlen and Halbach Foundation.

"Both authors contributed equally to this article.
Respiratory muscle weakness is the inevitable consequence of many childhood neuromuscular disorders (NMD). It causes severe ventilatory restriction, results in progressive respiratory failure, and is the major cause of early death. Respiratory failure relates directly to the loss of respiratory muscle force and vital capacity and shows characteristic evolution from normal ventilation during daytime and sleepinduced hypopnoeas at mild degrees of ventilatory restriction, to rapid eye movement (REM) and non-REM sleep hypoventilation in severe ventilatory restriction $[1,2]$. Continuous hypoventilation, common at inspiratory vital capacity (IVC) $<40 \%$ predicted, precedes daytime hypercapnia. Daytime respiratory failure is highly prevalent at IVC $<20 \%$ pred [2], and represents an accepted indication for supportive noninvasive (positive-pressure) ventilation (NIV). NIV, applied intermittently and preferably during sleep, relieves respiratory muscles from the work of breathing and augments alveolar ventilation [3-5].

In adolescents with Duchenne muscular dystrophy (DMD) and adults with various slowly progressive NMD or restrictive thoracic disease it has been shown that NIV applied during sleep, consistently improves diurnal and nocturnal gas exchange [5-8], symptoms and quality of life [9-12] and survival $[6,13]$. NIV, therefore, is considered as a highly effective treatment of chronic respiratory failure due to NMD and a consensus conference has recently published guidelines on the initiation of NIV including NMD [14]. Evidence of benefit, however, is only based on nonrandomised studies and remains scant in the paediatric setting, particularly in NMD other than DMD $[15,16]$. One earlier study of 10 children with nocturnal hypoventilation reported effective treatment but poor tolerance in patients $<10$ yrs [17]. Another recent study including mixed NMD reported immediate improvements of nocturnal gas exchange in 21 subjects and good mask tolerance over time, but presented no long-term data on gas exchange or lung function [18]. The gap between expanding use of NIV in the paediatric setting and understanding of its long-term effects in children therefore remains wide [19].

The present authors conducted this study to prospectively investigate the effects of nocturnal NIV on: 1) daytime and nocturnal gas exchange, 2) sleep and sleep-disordered 
breathing (SDB), and 3) lung and respiratory muscle function in children with DMD and a wide variety of NMD other than DMD over a period of $3 \mathrm{yrs}$.

\section{Methods}

\section{Subjects}

Since 1997 nocturnal NIV had been started in 38 children with progressive NMD. Eight children had been excluded from the study; six $<5$ yrs because no lung function could be obtained and two because no regular follow-up had been possible. The remaining 30 children and adolescents, 16 female and 14 male (aged 12.3 \pm 4.1 yrs, range 6-19 yrs) were studied.

Indications for NIV were daytime ventilatory insufficiency $(n=14)$ or symptomatic SDB $(n=16)$. Nine subjects had congenital muscular dystrophy $(12.2 \pm 3.4 \mathrm{yrs})$, five had DMD $(16.6 \pm 1.5 \mathrm{yrs})$, six had intermediate spinal muscular atrophy

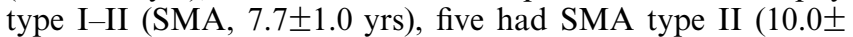
$3.3 \mathrm{yrs})$, two had the juvenile type of acid maltase deficiency (17 and 19 yrs) and one each had hereditary motor and sensor neuropathy type I (12 yrs), centronuclear myopathy (8 yrs), or nemaline myopathy (14 yrs). A paediatric neurologist had assessed all patients and the diagnosis had been confirmed at the histopathological and at the molecular level where applicable. Eighteen patients (10 subjects with SMA, seven with CMD and one with DMD) experienced $\geqslant 3$ chest infections per year necessitating antibiotic treatment. Twentythree subjects had moderate-to-severe scoliosis of whom 14 underwent spinal stabilisation prior to initiation of NIV, 24 subjects were wheelchair users.

\section{Lung and respiratory muscle function}

IVC, forced expiratory volumes (forced vital capacity (FVC), forced expiratory volume in one second (FEV1)) and peak inspiratory muscle pressure (PIP) were measured with a handheld spirometer/manometer (ZAN Meßgeräte, Obertulba, Germany). The best of three consistent efforts ( $<5 \%$ variability) was used. Predicted values of IVC were derived from published data $[20,21]$, predicted values of PIP $(\mathrm{kPa})$ were calculated with the equation $2.43+($ age $\times 0.34)$ [21]. Arterial blood gas tensions were determined on room air from arterialised ear lobe blood in an automated blood gas analyser (AVL 500, AVL LIST; GmbH Medizintechnik, Graz, Austria). Ventilatory insufficiency was defined as daytime carbon dioxide arterial tension $\left(\mathrm{Pa}, \mathrm{CO}_{2}\right)>6 \mathrm{kPa}(>45 \mathrm{mmHg})$.

\section{Sleep studies}

Initial sleep studies were performed as full polysomnography $(\mathrm{PSG}, \mathrm{n}=22)$ or cardiorespiratory polygraphy $(\mathrm{n}=8)$ including transcutaneous partial pressure of carbon dioxide ( $P$ tc, $\mathrm{CO}_{2}$ Radiometer, Copenhagen, Denmark) measurements. They were recorded onto a computerised work station (Embla 2.0, Flaga Medical Devices, Reykjavik, Iceland) scored manually and interpreted according to current guidelines $[22,23]$. The $P \mathrm{tc}, \mathrm{CO}_{2}$-device was calibrated before every measurement and adjusted to the patient's $P \mathrm{a}, \mathrm{CO}_{2}$. No oxygen was supplemented. Studies were terminated prematurely in two subjects, one with diurnal respiratory failure and the other with severe nocturnal hypoxaemia, for immediate institution of NIV. SDB was considered present if the respiratory disturbance index was $>10$ events per hour, and nocturnal hypoventilation was defined as $P \mathrm{tc}, \mathrm{CO}_{2}>6.7 \mathrm{kPa}$ ( $>50 \mathrm{mmHg}$ ) for $>50 \%$ of total sleep time [24].

\section{Technique of noninvasive ventilation}

NIV was applied by pressure-preset ventilators cycling in pressure-assist mode (BIPAP harmony; Respironics, Murrisville, PA, USA; Helia; Saime, Savigny Le Temple, France; VPAP II ST; Resmed Ltd., Sydney, Australia). Ventilator settings were chosen at the bedside with help of individual pressure-volume titration curves, and with the aim to increase tidal ventilation, suppress patient respiratory trigger effort, and optimise patient-ventilator synchrony. Adjustments were made during the following overnight sleep study with the aim of normalisation gas exchange (mean oxyhaemoglobin saturation $\left(\mathrm{Sa}, \mathrm{O}_{2}\right) \geqslant 95 \%$ and mean $P \mathrm{tc}, \mathrm{CO}_{2} \leqslant 6.7 \mathrm{kPa}$ $(\leqslant 50 \mathrm{mmHg}))$ and completely suppressing SDB. Ventilator setting averaged as follows: inspiratory positive airway pressure $13.9 \pm 3.1 \mathrm{cmH}_{2} \mathrm{O}$ (range $8-19 \mathrm{cmH}_{2} \mathrm{O}$ ), expiratory positive airway pressure $4.4 \pm 1 \mathrm{cmH}_{2} \mathrm{O}$ (range $3-8 \mathrm{cmH}_{2} \mathrm{O}$ ), backup respiratory rate $19.6 \pm 2.5$ beats per minute $(\mathrm{bpm})$ (range 14-24 bpm).

Masks were selected to ensure comfortable but air-tight seal. The mirage full face mask (Resmed, Sydney, Australia, $\mathrm{n}=10$ ) was used most frequently, besides custom-made masks [25] covering nose and mouth $(n=7)$ and nose only $(n=8)$, and other commercial nose masks $(n=5)$. Ventilators for patients using a face mask were equipped with battery and low pressure and power failure alarms. Patients and caregivers were trained in equipment use. Eighteen subjects with frequent chest infections or a peak cough flow $<150 \mathrm{~L} \cdot \mathrm{min}^{-1}$ were also instructed in assisted coughing using an intermittent positive-pressure breathing device for hyperinsufflation.

\section{Follow-up}

Follow-up after initial investigation and institution of NIV was at $3-6(n=30), 12-18 \quad(n=30), 24-30 \quad(n=20)$, and $\geqslant 36$ months $(\mathrm{n}=9)$. It included lung and respiratory muscle function tests, arterial blood gas (ABG) on room air after at least $8 \mathrm{~h}$ of spontaneous breathing, and PSG/polygraphy with capnometry during nocturnal NIV. Changes of ventilator settings or masks were made where necessary. Selfreported NIV use was controlled by reviewing the gauge of the ventilator. Thirteen patients were included in a study examining the impact of NIV on quality of life [9, 12].

\section{Withdrawal from noninvasive ventilation}

After at least 6 months of successful NIV all patients were asked to take a 3 night break from NIV prior to the following control visit. It was emphasised that patients should resume NIV in case of recurring symptoms. Ten of the 30 patients who completed the trial were re-evaluated after 3 nights without NIV and after 2 nights resumption of NIV.

\section{Statistical analysis}

Influence of NIV on gas exchange, lung function and sleep was analysed using the paired Wilcoxon test and the Spearman's rank correlation test. Group comparison between the distinct NMD and the impact of NIV withdrawal was tested using analysis of variance (ANOVA). All results are presented as mean \pm SD. The $p$-value $p<0.05$ was considered as significant. 
Table 1. - Influence of noninvasive ventilation (NIV) on nocturnal and daytime gas exchange

\begin{tabular}{|c|c|c|c|c|c|c|c|c|c|c|}
\hline \multirow[t]{2}{*}{ NMD } & \multirow{2}{*}{$\begin{array}{c}\text { Patients } \\
\mathrm{n}\end{array}$} & \multirow{2}{*}{$\begin{array}{l}\text { Duration } \\
\text { month }\end{array}$} & \multicolumn{2}{|c|}{$\mathrm{Sa}, \mathrm{O}_{2} \%$} & \multicolumn{2}{|c|}{$\mathrm{Ptc}, \mathrm{CO}_{2} \mathrm{mmHg}$} & \multicolumn{2}{|c|}{$P \mathrm{a}, \mathrm{O}_{2} \mathrm{mmHg}$} & \multicolumn{2}{|c|}{$\mathrm{Pa}, \mathrm{CO}_{2} \mathrm{mmHg}$} \\
\hline & & & $\begin{array}{l}\text { Before } \\
\text { NIV }\end{array}$ & $\begin{array}{l}\text { During } \\
\text { NIV }\end{array}$ & $\begin{array}{l}\text { Before } \\
\text { NIV }\end{array}$ & $\begin{array}{l}\text { During } \\
\text { NIV }\end{array}$ & $\begin{array}{l}\text { Before } \\
\text { NIV }\end{array}$ & $\begin{array}{l}\text { After } \\
\text { NIV }\end{array}$ & $\begin{array}{l}\text { Before } \\
\text { NIV }\end{array}$ & $\begin{array}{l}\text { After } \\
\text { NIV }\end{array}$ \\
\hline MD & 5 & $29.4 \pm 9.8$ & & & & & & $88.8 \pm 11.6$ & & $41.9 \pm 2.4$ \\
\hline Congenital MD & 9 & $20.7 \pm 10.9$ & $89.7 \pm 8.9$ & $96.2 \pm 1$ & $56.6 \pm 8.1$ & $42.2 \pm 3.9 * *$ & $74.5 \pm 20.5$ & $85.6 \pm 7.5$ & $49.7 \pm 12.1$ & $41.1 \pm 2.7$ \\
\hline Neuropathy & 12 & $25.3 \pm 11.7$ & $92.5 \pm 5.9$ & $96.7 \pm 2$ & $48.7 \pm 8.9$ & $40.0 \pm 4.8$ & $80.7 \pm 18.1$ & $89.8 \pm 12.7^{*}$ & $41.9 \pm 10.1$ & $38.6 \pm 3.7$ \\
\hline opathies & 4 & $30.0 \pm 21.8$ & $81.2 \pm 10.0$ & $96.2 \pm 0.5^{* *}$ & $64.5 \pm 12.8$ & $43.8 \pm 2.8 * *$ & $65.3 \pm 18.8$ & $93.3 \pm 8.8$ & $60.9 \pm 12.8$ & $44.1 \pm 3.3^{* *}$ \\
\hline Mean \pm SD & 30 & $25.3 \pm 12.6$ & $90.5 \pm 7.9$ & $96.3 \pm 1.5^{* * *}$ & $53.7 \pm 9.9$ & $41.6 \pm 4.8 * * *$ & $77.2 \pm 18.6$ & $88.8 \pm 10.4^{* * *}$ & $47.5 \pm 11.9$ & $40.6 \pm 3.6^{* * *}$ \\
\hline
\end{tabular}

$\mathrm{Pa}, \mathrm{O}_{2}$ : arterial oxyhaemoglobin tension; $\mathrm{Pa}, \mathrm{CO}_{2}$ : arterial carboxyhaemoglobin tension; $\mathrm{Sa}, \mathrm{O}_{2}$ : mean nocturnal oxyhaemoglobin saturation; $\mathrm{Ptc}, \mathrm{CO}_{2}$ : mean nocturnal transcutaneous carboxyhaemoglobin tension; NMD: neuromuscular disorders; Muscular dystrophy (MD) comprised four subjects with Duchenne muscular dystrophy and one subject with Becker muscular dystrophy, neuropathy comprised 11 subjects with spinal muscular atrophy and one subject with hereditary motor and sensor neuropathy type I, other myopathies comprised two subjects with juvenile type of acid maltase deficiency, one with nemaline myopathy and one with centronuclear myopathy. Conversion factor for $\mathrm{mmHg}$ to $\mathrm{kPa}(\times 0.133)$. *: $\mathrm{p}<0.05$; **: $\mathrm{p}<0.01 ; * * *: \mathrm{p}<0.001$.

\section{Results}

The observation period (time from institution of NIV to the latest follow-up) averaged $25.3 \pm 12.7$ months (range $8-60$ months, table 1). During the observation period patients' height and weight increased from $141 \pm 21 \mathrm{~cm}$ to $145 \pm 20 \mathrm{~cm}$ and $32.8 \pm 20.4 \mathrm{~kg}$ to $35.8 \pm 20.7 \mathrm{~kg}$, respectively $(\mathrm{p}<0.005)$.

In 26 patients/parents self-reported use of nocturnal NIV was $8-12 \mathrm{~h}$ during at least 6 nights a week. Four patients/ parents reported an intermitted use of 3-4 h of sleep during most days of the week. Eight patients used NIV intermittently during naps and episodes of upper airway infections. Patients/ parents reports were concordant to the ventilator gauge in all cases.

\section{Noninvasive ventilation effect on gas exchange}

Long-term NIV improved or normalised mean $\mathrm{Sa}, \mathrm{O}_{2}$ and $P$ tc,, $\mathrm{CO}_{2}(90.5 \pm 7.9 \%$ to $96.3 \pm 1.5 \%$ and $7.1 \pm 1.3 \mathrm{kPa}$ to $5.5 \pm 0.6 \mathrm{kPa}(53.7 \pm 9.9 \mathrm{mmHg}$ to $41.6 \pm 4.8 \mathrm{mmHg}), \mathrm{p}<0.001)$, nadir $\mathrm{Sa}, \mathrm{O}_{2}$, maximum $P \mathrm{tc}, \mathrm{CO}_{2}$ and per cent of sleep time spent in hypoxaemia and hypercapnia (fig. 1). Nocturnal heart rate dropped from $104.7 \pm 14.3 \mathrm{bpm}$ pre-ventilation to $86.4 \pm 12.6$ bpm during NIV $(\mathrm{p}<0.01)$.

NIV also caused sustained improvement in daytime gas exchange, apparent from ABG drawn $\geqslant 8 \mathrm{~h}$ of spontaneous breathing (table 1). In the patients with diurnal ventilatory insufficiency $(\mathrm{n}=14)$ arterial oxygen tension $\left(\mathrm{Pa}, \mathrm{O}_{2}\right)$ increased from $8.7 \pm 1.8$ to $11.3 \pm 1.1 \mathrm{kPa}(65.3 \pm 13.2$ to $85.1 \pm 8.5 \mathrm{mmHg})$, $\mathrm{pH}$ from 7.33 \pm 0.05 to $7.38 \pm 0.03$, and $\mathrm{Pa}_{2} \mathrm{CO}_{2}$ fell from $7.5 \pm 1.3$ to $5.7 \pm 0.3 \mathrm{kPa}(56.4 \pm 9.5$ to $42.8 \pm 2.6 \mathrm{mmHg}) \quad(\mathrm{p}<0.01$ for all). Individual data are shown in figure 2 .

\section{Noninvasive ventilation effect on sleep and sleep-disordered breathing}

Paired full PSG before initiation of NIV and during NIV could be performed in 17 patients. NIV effectively suppressed SDB and improved sleep (table 2). During NIV respiratory disturbances and associated electroencephalogram (EEG)arousals normalised. The proportion of light sleep (stage 1 and 2) decreased and slow wave sleep (stage 3 and 4) increased.

\section{Withdrawal from noninvasive ventilation}

Eight patients refused NIV-withdrawal, 12 made an attempt but resumed back to NIV mainly during the first night because significant symptoms occurred. Finally ten patients, seven with diurnal respiratory failure and three with SDB, completed 3 nights without NIV. In these patients withdrawal resulted in prompt deterioration of nocturnal and diurnal hypoventilation nearly back to baseline. Resumption of NIV during the following nights immediately normalised nocturnal respiration and diurnal blood gases within 2 nights/days (fig. 3). There was no significant difference in lung and respiratory muscle function between the measures made after withdrawal and after resumption of NIV.
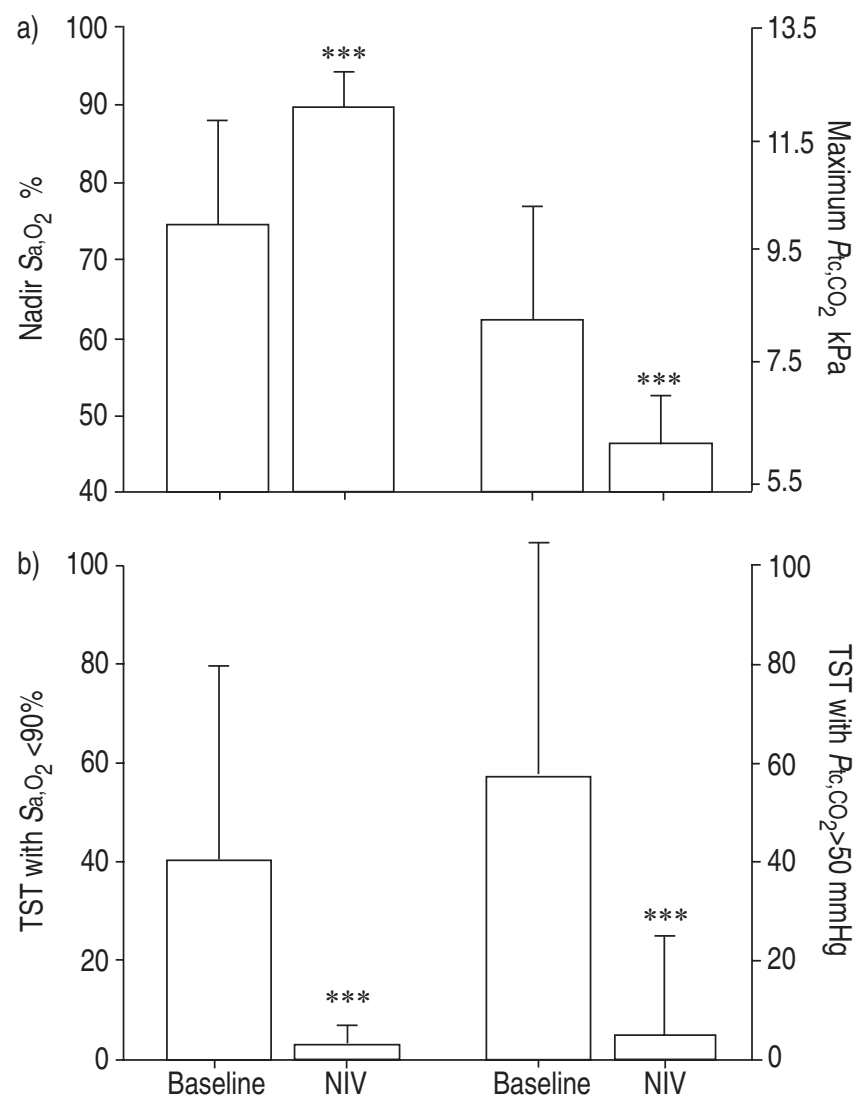

Fig. 1.-a) Impact of noninvasive ventilation (NIV) on nadir oxyhaemoglobin saturation $\left(\mathrm{Sa}_{\mathrm{a}} \mathrm{O}_{2}\right)$ and maximum transcutaneous carbon dioxide tension $\left(P_{\mathrm{tc},} \mathrm{CO}_{2}\right)$, and $\left.\mathrm{b}\right)$ on sleep time spent with hypoxaemia and hypercapnia. Baseline study before institution of NIV and during NIV at the latest control visit $25.3 \pm 12.7$ months later. \% TST: per cent of total sleep time; $\mathrm{n}=30 ;{ }^{* * *}: \mathrm{p}<0.001$. 

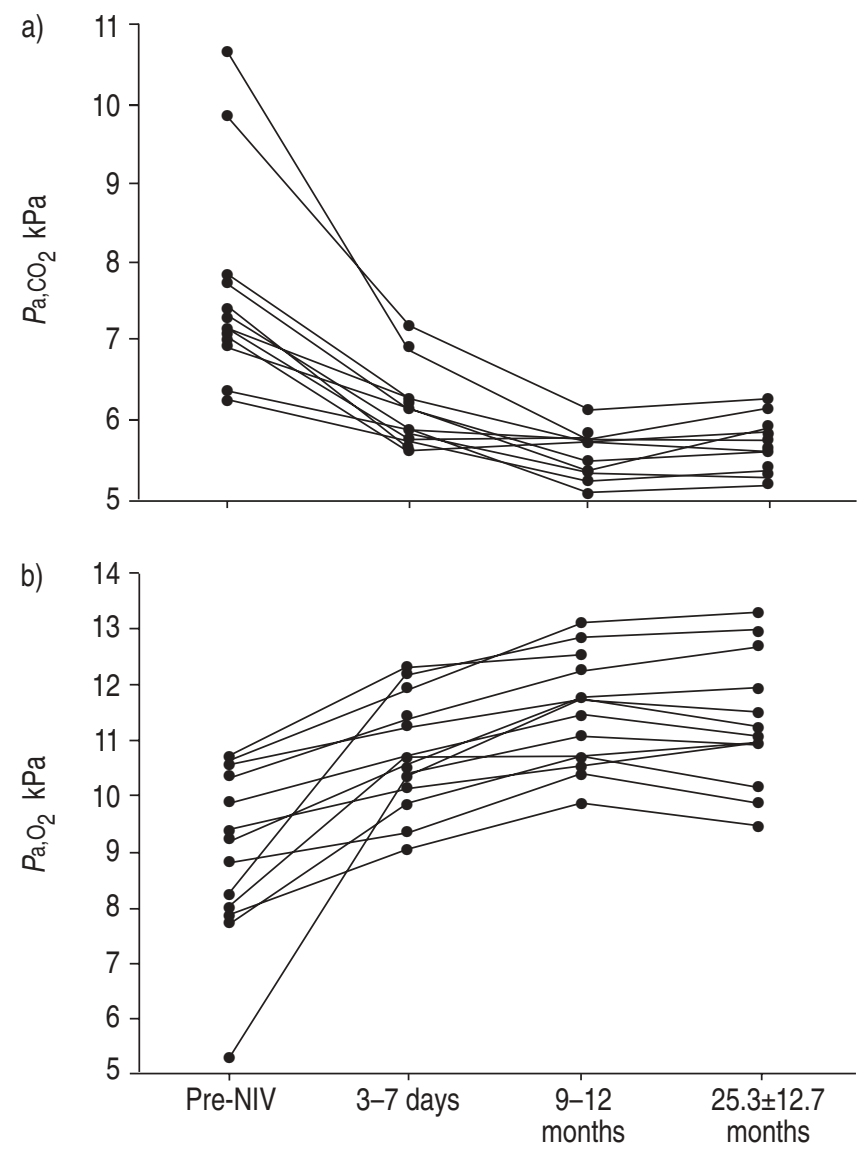

Fig. 2.-Impact of noninvasive ventilation (NIV) on a) diurnal

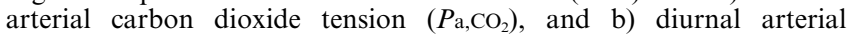
oxygen tension $\left(\mathrm{Pa}_{\mathrm{a}} \mathrm{O}_{2}\right)$ before institution (pre-NIV), 3-7 days after institution of NIV, at a control visit 9-12 months after institution of NIV and at the latest control visit at $25.3 \pm 12.7$ months. Blood gas samples were obtained after at least $8 \mathrm{~h}$ spontaneous breathing. $\mathrm{n}=14$; $\mathrm{p}<0.001$ for the difference between blood gas tensions before (preNIV) and at any of the controls after initiation of NIV.

\section{Noninvasive ventilation effect on lung and respiratory muscle function}

Restrictive ventilatory defect (IVC $27.2 \pm 15.3 \%$ ) was present in all patients at study entry. During the observation period IVC decreased by $82 \pm 246 \mathrm{~mL}$, or $2 \%$ predicted per year. Change in IVC varied among the different diagnostic entities of NMD (table 3). It declined $183 \pm 111 \mathrm{~mL} \cdot \mathrm{yr}^{-1}$ in adolescents with DMD, who did not grow and had no progression of scoliosis, but on average did not change

Table 2. - Influence of noninvasive ventilation (NIV) on sleepdisordered breathing and sleep

\begin{tabular}{lccc}
\hline & Before NIV & During NIV & p-value \\
\hline RDI $\cdot \mathrm{h}^{-1}$ & $10.5 \pm 13.1$ & $3.1 \pm 3.5$ & $<0.001$ \\
REM-RDI $\cdot \mathrm{h}^{-1}$ & $20.5 \pm 21.1$ & $3.0 \pm 5.3$ & $<0.001$ \\
Arousal index $\cdot \mathrm{h}^{-1}$ & $20.6 \pm 14.3$ & $10.2 \pm 3.8$ & $<0.001$ \\
Light-sleep \% & $55 \pm 12$ & $44 \pm 13$ & $<0.05$ \\
Slow-wave-sleep \% & $24 \pm 9$ & $34 \pm 9$ & $<0.05$ \\
REM-sleep \% & $18 \pm 6$ & $20 \pm 6$ & 0.18 \\
\hline
\end{tabular}

RDI: respiratory disturbance index per hour sleep; REM-RDI: respiratory disturbance index per hour rapid eye movement (REM)sleep; arousal index: electrocephalographic arousals per hour sleep.
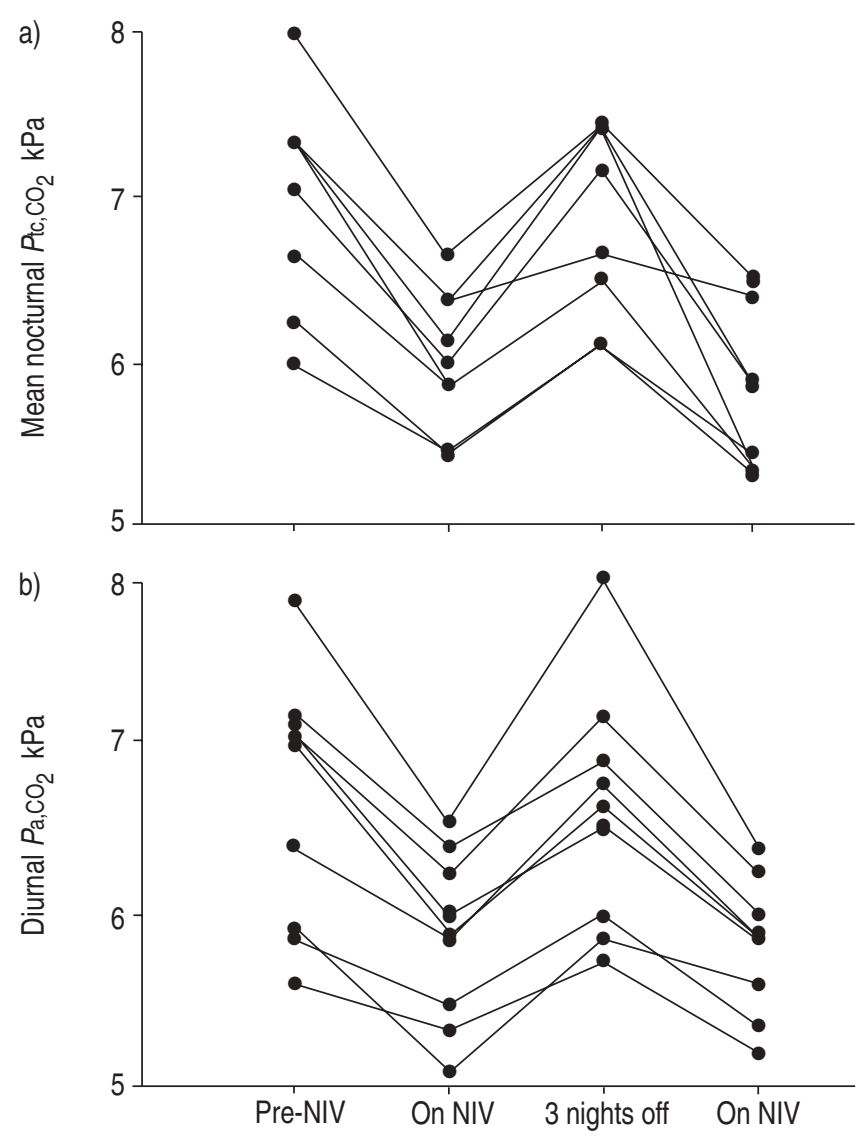

Fig. 3. - Impact of noninvasive ventilation (NIV) withdrawal on a) nocturnal transcutaneous carbon dioxide tension $\left(P_{\mathrm{tc},} \mathrm{CO}_{2}\right)$ and $\left.\mathrm{b}\right)$ diurnal arterial carbon dioxide tension $\left(P_{\left.\mathrm{a}, \mathrm{CO}_{2}\right)}\right.$. Measurements were obtained before institution of treatment (pre-NIV), at a subsequent control visit (on NIV), after 3 nights NIV-withdrawal ( 3 nights off) and after 2 days re-institution of NIV. Blood gas samples were obtained after at least $8 \mathrm{~h}$ spontaneous breathing. $\mathrm{n}=10 ; \mathrm{p}<0.001$ (ANOVA) for the differences between all measurements at the different dates (between pre-NIV and on NIV, on NIV and 3 nights off, and 3 nights off and the following control on NIV).

significantly in patients with other conditions. In the younger children with SMA and congenital muscular dystrophies, the majority of the study patients, IVC course was highly heterogeneous, showing improvement in seven, stability in five, and slow or rapid decline in nine patients, associated with the progression of scoliosis.

Inspiratory muscle pressure, too, was severely impaired prior to NIV. It improved slightly from $2.5 \pm 1.2 \mathrm{kPa}(40 \pm 20$ $\%$ pred) to $2.8 \pm 1.2 \mathrm{~cm} \mathrm{kPa}(44 \pm 20 \%$ pred., $\mathrm{p}=0.11)$. This effect was observed in all patients, irrespective of NMD entity.

\section{Outcome}

No patient died or experienced life threatening complications during the study period. Four patients required a total of six hospital admissions due to chest infections, amounting to 0.2 admissions per patient and year. All patients reported relevant improvement of symptoms. In 13 patients who had completed a validated questionnaire, a highly significant and relevant improvement in quality of life had been demonstrated $[9,12,26]$. 
Table 3. - Influence of noninvasive ventilation (NIV) on inspiratory vital capacity (IVC)

\begin{tabular}{|c|c|c|c|c|c|c|}
\hline \multirow[t]{2}{*}{ NMD } & \multirow[t]{2}{*}{ Patients $\mathrm{n}$} & \multicolumn{2}{|c|}{ IVC mL } & \multicolumn{2}{|c|}{ IVC \% } & \multirow{2}{*}{$\begin{array}{c}\text { IVC-change } \\
\mathrm{mL} \cdot \mathrm{yr}^{-1}\end{array}$} \\
\hline & & Before NIV & With NIV & Before NIV & With NIV & \\
\hline MD & 5 & $1200 \pm 670$ & $776 \pm 464^{*}$ & $26.2 \pm 11.4$ & $16.2 \pm 7.3^{*}$ & $-183 \pm 111^{*}$ \\
\hline Congenital MD & 9 & $514 \pm 305$ & $493 \pm 212$ & $21.3 \pm 6.9$ & $19.4 \pm 7.0$ & $2.4 \pm 91.7$ \\
\hline Neuropathy & 12 & $601 \pm 506$ & $578 \pm 443$ & $32.5 \pm 21.3$ & $25.4 \pm 14.0$ & $1.8 \pm 65.5$ \\
\hline Other myopathies & 4 & $717 \pm 207$ & $747 \pm 327$ & $25.8 \pm 8.7$ & $22.3 \pm 9.0$ & $38.3 \pm 92.5$ \\
\hline Mean \pm SD & 30 & $690 \pm 493$ & $608 \pm 374$ & $27.2 \pm 15.3$ & $21.7 \pm 10.8^{* *}$ & $-23.9 \pm 109.3^{*}$ \\
\hline
\end{tabular}

NMD: neuromuscular disorders; Muscular dystrophy (MD) comprised four subjects with Duchenne muscular dystrophy and one subject with Becker muscular dystrophy, neuropathy comprised 11 subjects with spinal muscular atrophy and one subject with hereditary motor and sensor neuropathy type I, other myopathies comprised two subjects with juvenile type of acid maltase deficiency, one with nemaline myopathy and one with centronuclear myopathy. ${ }^{*}: \mathrm{p}<0.05 ; * *$ p $<0.01$.

\section{Discussion}

NIV over the past years has become standard therapy for acute and chronic respiratory failure of various causes, including adult neuromuscular diseases [27]. NIV improves gas exchange by increasing tidal ventilation, unloading respiratory muscles, and possibly by resetting respiratory centre chemosensitivity [4, 28, 29]. Favourable impact on morbidity, survival, and quality of life has been shown in adult neuromuscular disease and in adolescents with DMD, a disease of gradual and highly predictable progression [6, 13, $30,31]$. The evidence for benefit in other NMD is less clear, in part because concerns over undue prolongation of severely handicapped life, mask intolerance, and uncertainty about appropriate timing of initiation of NIV have hampered its widespread application. Concerns are likely to abate, however, over a recent report of NIV's beneficial effect on gas exchange and good mask tolerance over time in even small children with NMD other than DMD [18].

The present study confirms the beneficial effect on gas exchange, but expands upon the existing data by demonstrating the consistency of the effect over an observation period of up to $5 \mathrm{yrs}$, coupled with marked improvement of sleep quality, stabilisation of lung and respiratory muscle function, and rapid deterioration of gas exchange during brief ventilation pause.

NIV was instituted with the objective of achieving normocapnia during ventilation. The goal that was realised within 3-7 days of hospitalisation using flow-triggered, pressurecontrolled modes of ventilation and, when necessary customised masks that covered the nose and mouth, minimised dead-space and air leaks and facilitated ventilator cycling. Much bedside effort went into finding optimal ventilator settings. When effectively unloaded, spontaneous respiratory rate quickly dropped to back-up rate, nocturnal heart rate dropped $15 \%$ from baseline and patients generally fell asleep shortly after initiation of ventilation.

Gas exchange normalised rapidly in the early treatment phase, and continued to improve over the first few months. Improvements of gas exchange persisted through the daytime interval of spontaneous breathing, an observation that has previously been reported and attributed to the resetting of the ventilatory control centre $[4,28]$.

The deleterious effects of respiratory muscle weakness, however, were demonstrated by rapid though fully reversible deterioration of nocturnal and diurnal gas exchange during only 3 days of ventilation pause in ten patients. In contrast to the study of HiLL et al. [4] that included six adults with mainly restrictive chest wall disorders in whom 1 week withdrawal from NIV did not alter diurnal blood gases, in children with advanced respiratory muscle weakness the regular nightly use of NIV seems to be necessary to maintain the gains achieved.
By extending the indication for NIV to patients with symptomatic sleep hypopnoeas and nocturnal hypercapnia the question of appropriate timing of initiation of NIV is raised. Many neuromuscular diseases, particularly those included in the present study, are characterised by diffuse respiratory muscle involvement and progressive decline of lung and respiratory muscle function. SDB, nocturnal and diurnal hypercapnic hypoventilation are common complications that evolve as a function of ventilatory restriction [1, 2, 8]. Institution of NIV for symptomatic sleep hypopneas, although not recommended in a recent Cochrane Review [32] seems justified in the light of anticipated progression to nocturnal hypoventilation and chronic hypercapnia that is blunting central respiratory drive and probably triggering subsequent daytime respiratory failure. [4, 5]. Moreover, NIV improved sleep quality, evident by an increase in sleep efficiency and deep sleep, and a reduction of light sleep and arousals.

One limitation of the study is that symptoms and quality of life have not been followed systematically. However, 20 patients including 13 who had only SDB refused withdrawal from NIV because they had experienced significant symptoms when sleeping without NIV. All 10 patients who withdrew NIV experienced reappearance of sleep disturbance and daytime symptoms and had some difficulties tolerating the 3 nights without NIV. This simple trial and the children's excellent compliance is providing convincing evidence that objective improvements in sleep during nocturnal ventilation go along with subjective improvements that are perceived as very beneficial. Furthermore 13 of the patients in the current study were included in another study and reported significant and relevant relief of symptoms and improvement in quality of live $[9,12]$.

The current authors strongly feel that it is no longer justified to withhold an effective therapy that is otherwise generally accepted in conditions such as nocturnal hypoventilation due to obesity or chronic obstructive pulmonary disease (COPD) from severely handicapped and symptomatic children.

NIV's effects on lung function are less clear, in part because data on the natural course of lung function changes are scarce. In the non-DMD patients lung function stayed fairly stable or even improved slightly. In these patients a relevant decline in IVC was always accompanied by a progression of scoliosis. In contrast IVC decline was most pronounced in DMD patients. They lost $183 \mathrm{~mL}$ per year, an amount that is equal to the $200 \mathrm{~mL} \cdot \mathrm{yr}^{-1}$ previously reported [33].

Expectedly, inspiratory muscle pressure was markedly reduced in all patients. In contrast to previous observations in adults [34] it did not deteriorate but improved slightly during the ventilation period, in the DMD male children despite concurrent decline of vital capacity. This might suggest 
that respiratory muscle rest and resetting of respiratory centre set point for $\mathrm{CO}_{2}$ were the predominant mechanisms.

In summary, the present study shows that prolonged use of noninvasive ventilation is well tolerated and highly effective in reversing sleep-disordered breathing and chronic respiratory failure in children with neuromuscular diseases. Therefore, a regular and systematic evaluation including sleep studies is essential. Noninvasive ventilation should be recommended in children with sleep-disordered breathing when an initial trial is tolerated and symptoms improve, but it is mandatory long term once respiratory failure occurs.

\section{References}

1. Mellies U, Ragette R, Schwake C, Boehm H, Voit T, Teschler H. Daytime predictors of sleep disordered breathing in children and adolescents with neuromuscular disorders. Neuromuscular Disorders 2002; 13: 123-128.

2. Ragette R, Mellies U, Schwake C, Voit T, Teschler H. Patterns and predictors of sleep disordered breathing in primary myopathies. Thorax 2002; 57: 724-728.

3. Ellis ER, Grunstein RR, Chan S, Bye PT, Sullivan CE. Noninvasive ventilatory support during sleep improves respiratory failure in kyphoscoliosis. Chest 1988; 94: 811815.

4. Hill NS, Eveloff SE, Carlisle CC, Goff SG. Efficacy of nocturnal nasal ventilation in patients with restrictive thoracic disease. Am Rev Respir Dis 1992; 145: 365-371.

5. Hukins CA, Hillman DR. Daytime predictors of sleep hypoventilation in Duchenne muscular dystrophy. Am J Respir Crit Care Med 2000; 161: 166-170.

6. Simonds AK, Muntoni F, Heather S, Fielding S. Impact of nasal ventilation on survival in hypercapnic Duchenne muscular dystrophy. Thorax 1998; 53: 949-952.

7. Vianello A, Bevilacqua M, Salvador V, Cardaioli C, Vincenti E. Long-term nasal intermittent positive pressure ventilation in advanced Duchenne's muscular dystrophy. Chest 1994; 105: 445-448.

8. Mellies U, Ragette R, Schwake C, Baethmann M, Voit T, Teschler H. Sleep disordered breathing and respiratory failure in acid maltase deficiency. Neurology 2001; 57: 1290-1295.

9. Paditz E, Zieger S, Bickhard J, et al. Lebensqualität unter Heimbeatmung im Kindes-, Jugend- und juiden Erwachsenenalter: underschiedliche Sichtweisen von Eltem und Kindern [Self-Reported quality of life in home mechanical ventilation in childhood, adolescence and young adulthood: differences between parents and children]. Somnologie 2000; 4: $13-19$.

10. Pehrsson K, Olofson J, Larsson S, Sullivan M. Quality of life of patients treated by home mechanical ventilation due to restrictive ventilatory disorders. Respir Med 1994; 88: 21-62.

11. Wiebel M, Schulz M, Jackowski M, Schulz V. Lebensqualität und Langzeitüberleben mit intermittierndser Selbstbeatmung bei respiratorischer Insuffizienz durch restriktive Thoraxerkrankungen [Quality of life and long-term survival with intermittent self-ventilation in respiratory insufficiency caused by thoracic restrictive diseases]. Med Klin 1996; 91 : Suppl. 2, 19-21.

12. Paditz E, Zieger S, Koch R. Lebensqualität unter intermittierender Heinbeatmung [Quality of life with intermittent positive pressure ventilation]. Monatsschr Kinderheilkd 2003; 151: 284-291.

13. Eagle M, Baudouin S, Chandler C, Giddings D, Bullock R, Bushby K. Survival in Duchenne muscular dystrophy: improvements in life expectancy since 1967 and the impact of home nocturnal ventilation. Neuromuscul Disord 2002; 12 : 926-929.

14. Clinical indications for noninvasive positive pressure ventilation in chronic respiratory failure due to restrictive lung disease, COPD, and nocturnal hypoventilation - a consensus conference report. Chest 1999; 116: 521-534.

15. Birnkrant DJ, Pope JF, Martin JE, Repucci AH, Eiben RM. Treatment of type I spinal muscular atrophy with noninvasive ventilation and gastrostomy feeding. Pediatr Neurol 1998; 18: 407-410.

16. Ellis ER, McCauley VB, Mellis C, Sullivan CE. Treatment of alveolar hypoventilation in a six-year-old girl with intermittent positive pressure ventilation through a nose mask. Am Rev Respir Dis 1987; 136: 188-191.

17. Heckmatt JZ, Loh L, Dubowitz V. Night-time nasal ventilation in neuromuscular disease. Lancet 1990; 335: 579-582.

18. Simonds AK, Ward S, Heather S, Muntoni F. Outcome of paediatric domiciliary mask ventilation in neuromuscular and skeletal disease. Eur Respir J 2000; 36: 476-481.

19. Fauroux B, Lofaso F. Noninvasive mechanical ventilation in children. Eur Respir Mon 2001; 6: 16, 244-258.

20. Zapletal A, Samanek M, Paul T. Lung function in children and adolescents. Methods, reference values. Prog Respir Res 1987; 22: 113-218.

21. Mellies U, Schultze S, Schwake C, Ragette R, Teschler H. Respiratory muscle function in 300 healthy children (abstract). Eur Respir J 2001; 18: Suppl. 33, 827.

22. Standards and indications for cardiopulmonary sleep studies in children. American Thoracic Society. Am J Respir Crit Care Med 1996; 153: 866-878.

23. ASDA. Recommendations for syndrome definition and measurement techniques in clinical research. Sleep 1999; 22: 667-689.

24. Marcus CL, Omlin KJ, Basinki DJ, et al. Normal polysomnographic values for children and adolescents. Am Rev Respir Dis 1992; 146: 1235-1239.

25. Mellies U. German pediatric masks. International ventilator users network news 2001; 15. Copyright 2002 Gazette International Networking Institute (GINI). http://www. post-polio.org/ivun/ivun15-3.html\#masks. Date updated: March 32003.

26. Twork S, Paditz EUS, Usicenko S, Ragette R, Bickhardt J. Importance of medical history in diagnosis of global respiratory failure in patients suffering from neuromuscular diseases and thoracic deformities. Wien Klin Wochenschr 2001; 113: 224-228.

27. Mehta S, Hill NS. Noninvasive ventilation. Am J Respir Crit Care Med 2001; 163: 540-577.

28. Piper AJ, Sullivan CE. Effects of long-term nocturnal nasal ventilation on spontaneous breathing during sleep in neuromuscular and chest wall disorders. Eur Respir J 1996; 9: $1515-1522$.

29. Rossi A, Appendini L, Roca J. Physiological aspects of noninvasive positive pressure ventilation. Eur Respir Mon 2001; 6(16): 1-10.

30. Simonds AK, Elliott MW. Outcome of domiciliary nasal intermittent positive pressure ventilation in restrictive and obstructive disorders. Thorax 1995; 50: 604-609.

31. Mohr CH, Hill NS. Long-term follow-up of nocturnal ventilatory assistance in patients with respiratory failure due to Duchenne-type muscular dystrophy. Chest 1990; 97: 9196.

32. Annane D, Chevrolet JC, Chevret S, Raphaël JC. Nocturnal mechanical ventilation for chronic hypoventilation in patients with neuromuscular and chest wall disorders (Cochrane Review). In: The Cochrane Library, Issue 3, 2002, www.update-software.com/cochrane/abstracts/ab001941. htm. Date accessed: April 12003.

33. Rideau Y, Jankowski LW, Grellet J. Respiratory function in the muscular dystrophies. Muscle Nerve 1981; 4: 155164.

34. Barbe F, Quera-Salva MA, de Lattre J, Gajdos P, Agusti AG. Long-term effects of nasal intermittent positive-pressure ventilation on pulmonary function and sleep architecture in patients with neuromuscular diseases. Chest 1996; 110: 11791183. 